\title{
Integrative approaches to investigate the structure and assembly of Trypanosoma brucei BILBO1, a multidomain cytoskeletal protein at the flagellar pocket collar
}

\author{
$K_{\text {K Vidilaseris }}{ }^{2}$, B Morriswood $^{2}, G$ Dong $^{1 *}$ \\ From Cilia 2014 - Second International Conference \\ Paris, France. 18-21 November 2014
}

Trypanosoma brucei is a protist parasite and the causative agent of Human African Trypanosomiasis (sleeping sickness). At the base of its single flagellum is a bulb-like structure called the flagellar pocket (FP). The FP is the site of all endo-/exocytosis and thus essential for the survival of the parasite. At the neck of the FP is an electron-dense cytoskeletal structure termed the flagellar pocket collar (FPC), which currently has only one known protein component, BILBO1. Bioinformatic analysis indicates that there are four structural domains in the $67-\mathrm{kDa}$ protein, including a globular N-terminal domain, two central EFhand motifs followed by a long coiled-coil domain, and a C-terminal leucine zipper. T. brucei BILBO1 (TbBILBO1) by itself forms insoluble oligomers in vitro, which makes it intractable to any single conventional structural study method. We recently carried out structural dissection of TbBILBO1 using integrative structural biology approaches including NMR, crystallography, EM, and various biophysical methods. The high-resolution structure of its $\mathrm{N}$-terminal domain reveals a variant ubiquitin-like fold with a conserved surface patch; mutagenesis of this patch causes cell death in vivo. We further found that the EF-hand motifs change their conformation upon calcium binding, the coiled-coil domain forms an antiparallel dimer, and intermolecular interactions between adjacent leucine zippers allow TbBILBO1 to form extended filaments in vitro. These filaments were additionally shown to condense into fibrous bundles through lateral interactions as demonstrated by our EM studies. Based on

'Department of Medical Biochemistry, Max F. Perutz Laboratories, Medical University of Vienna, Vienna, Austria

Full list of author information is available at the end of the article all these experimental data, we propose a mechanism for TbBILBO1 assembly into the flagellar pocket collar.

\section{Authors' details}

'Department of Medical Biochemistry, Max F. Perutz Laboratories, Medical University of Vienna, Vienna, Austria. ${ }^{2}$ Max F. Perutz Laboratories, University of Vienna, Vienna, Austria.

Published: 13 July 2015

\section{doi:10.1186/2046-2530-4-S1-P25}

Cite this article as: Vidilaseris et al:: Integrative approaches to investigate the structure and assembly of Trypanosoma brucei BILBO1, a multidomain cytoskeletal protein at the flagellar pocket collar. Cilia 2015 4(Suppl 1):P25.
Submit your next manuscript to BioMed Central and take full advantage of:

- Convenient online submission

- Thorough peer review

- No space constraints or color figure charges

- Immediate publication on acceptance

- Inclusion in PubMed, CAS, Scopus and Google Scholar

- Research which is freely available for redistribution
() Biomed Central 